\title{
La recepción del pensamiento maurrasiano en España (1914-1930)
}

\author{
Pedro Carlos González Cuevas *
}

\section{INTRODUCCIÓN}

Las ideologías políticas no pueden considerarse como cuerpos cerrados o estáticos de conocimiento, porque van evolucionando en las coyunturas y con el surgimiento de nuevas problemáticas a las que deben ir dando respuestas adecuadas, lo cual explica su pervivencia histórica y su capacidad de adaptación a las nuevas relaciones que el desarrollo social impone.

El tradicionalismo ideológico irá, a lo largo del siglo XIX, transformando sus pautas doctrinales, al calor, sobre todo, de la influencia de la filosofía positivista. Sería Charles Marie Pothius Maurras (1868-1952) el ideólogo que con mayor precisión repensó los principios fundamentales del tradicionalismo ideológico en el lenguaje de las corrientes positivistas, realizando una nueva síntesis que tendría un indudable impacto no sólo en Francia y en otros países europeos, sino igualmente en Hispanoamérica. Maurras es el sistematizador de las dispersas corrientes del conservadorismo francés que brotaron durante el siglo XIX en oposición al significado político y social de la Revolución de 1789. Se vio a sí mismo como el continuador de una línea de pensamiento multilateral, pero ininterrumpida, que buscaba su síntesis final. No obstante, como todas las síntesis importantes, su obra es algo más que una mera refundición; integra algunos de sus elementos y otros; los eleva de nivel y los pro-

* CSIC. 
yecta en una realidad social y política distinta. Joseph de Maistre, Louis de Bonald, Le Play, La Tour du Pin, Mistral, Comte, Taine, Renán, Fustel de Coulanges, Barrès e incluso Proudhon: todos ellos para Maurras, por debajo de sus indudables discrepancias, tenían secretas afinidades, que confluían, con sus críticas al liberalismo y a la democracia, en un proyecto de «regeneración nacional» para la salvación de Francia ${ }^{~}$.

Producto del ambiente positivista dominante en su país durante gran parte del siglo XIX, Maurras intentó dar un barniz cientificista a la construcción de su doctrina política, y pretendería, en todo momento, haber llegado a sus conclusiones por medios estrictamente inductivos y racionales. Maurras expurgaría al positivismo comteano de todos sus elementos utópicos y progresistas, convirtiéndole, desde su perspectiva, en un armazón ideológico profundamente conservador. La base filosófica del positivismo se encontraba en la subordinación de la «imaginación» a la "observación", de la «razón» a los «hechos", mediante la cual quedaba destruida la dimensión utópica del conocimiento. A partir de ese presupuesto, Maurras pretendió articular un método de análisis político, que designaría con el nombre de «empirismo organizador», que, planteando como requisito funcional prioritario la necesidad de orden en las sociedades, consistía en descubrir a partir de la sociología y la historia las «leyes» que dirigen la vida y la muerte de las sociedades; en interpretar estas «leyes» por la psicología, y en obtener, por último, los principios de acción política a través de aquellos datos ${ }^{2}$.

En sus análisis, Maurras partía de un concepto sumamente fijista del hombre y la sociedad. El orden social era concebido de forma rígida y cosificada. La idea de orden viene unida a la de jerarquía como sistema de organización de la parte al todo, de lo inferior a lo superior, del proceso al resultado. Siguiendo a Comte, Maurras asimila epistemológicamente la sociedad a la "naturaleza", que tiene una realidad objetiva, independiente de la voluntad humana, y obedece, por tanto, a sus propias «leyes", que han de descubrirse y a la que ha de plegarse la iniciativa de los indivíduos y de la especie. La sociedad es, pues, un «agregado natural», que se rige necesariamente por las «leyes» de jerarquía, selección, continuidad y herencia ${ }^{3}$. Su desarrollo consiste en la

1 Maurras, Charles, "Maîtres de L'Action Française", en Dittionnaire politique et critjque. Tome I. París, A la Cité des Livres, 1931, págs. 32-33.

2 Maurras, Charles, "Trois idées politiques", en Romantisme et Revolution. París. Nouvelle Librairie Nationale, 1922, págs. 262 y ss.

3 Maurras, Charles, "La politique religieuse", en La democratie religieuse. París. Nouvelles Editons Latines, 1978, pág. 289. 
elevación del grado de sociabilidad: a partir de la familia surgen, de manera cuasibiológica, una serie de asociaciones naturales que culminan en la Nación. La "Humanidad", el "Gran Ser", concebido por Comte como el conjunto de los seres pasados, presentes y futuros que concurren libremente a perfeccionar el orden universal, se convierte, en el sistema maurrasiano, en la Nación, definida como un entidad viva, orgánica, natural, formada, al mismo tiempo, por la historia a través de la tradición heredada de las distintas generaciones y destinada a perpetuarse en el futuro. Así concebida, la Nación, que para Maurras es el vínculo social más sólido y fructífero que subsistía en el mundo contemporáneo tras la destrucción del orden católico en el siglo XVII, excluía la autonomía de los individuos; era la unidad social por antonomasia, superior a los fraccionamientos clasistas en que se escindía la sociedad. De esta forma coincide, en la dialéctica maurrasiana, el orden como requisito social prioritario con el interés nacional ${ }^{4}$.

Conscientemente, la crítica de Maurras va a dirigirse contra toda la corriente ideológica que, poniendo énfasis en la conciencia individual, cuestionara las realidades objetivas forjadas por la «naturaleza» y por la historia. La obra crítica suponía remontarse a las fuentes intelectuales que desembocaban en el individualismo liberal triunfante en la Revolución de 1789; es decir, al «monstruo de las tres cabezas»: Reforma-Romanticismo-Revolución, fenómenos históricos que no eran más que el reflejo del proceso contemporáneo que seguía el sinuoso curso de la experiencia burguesa de libertad, y cuyo contenido profundo podía resumirse en una sola palabra: primacía del individuo. Al quebrantar el monopolio dogmático de la jerarquía eclesiástica, la reforma protestante inauguró, mediante la doctrina del «libre examen», el proceso ideológico que llevaba al liberalismo. La Revolución de 1789 no haría otra cosa que sacar las consecuencias últimas de las premisas protestantes; supuso el triunfo de las ideas individualistas en la sociedad francesa. $Y$ su proyecto político se basaba en el utópico empeño de instaurar una organización social a contracorriente de las «leyes» que regían la vida de los seres organizados y de las sociedades ${ }^{5}$. Las tendencias anarquizantes se daban igualmente en el arte y en la literatura. Maurras recorrió, en realidad, su itinerario intelectual desde la crítica literaria a la militancia política e ideo-

${ }^{4}$ Maurras, Charles, «Realités", en Oeuvres Capitales. Tome II. Essais politiques. París, Flammarion, 1954, pág. 264. MaurRas, Charles, Mes idées politiques. París, Fayard, 1937, págs. 257 y ss.

5 Maurras, Charles, "Le dilemme de Marc Sangnier", en La democratie religieuse. París, Nouvelles Editions Latines, 1978, pág. 113. 
lógica. El romanticismo literario y estético no era otra cosa que el triunfo del individualismo - sinónimo de desorden - en el ámbito de las artes, y cuyo origen se encontraba en Rousseau ${ }^{6}$.

La Revolución de 1789 fue, pues, una auténtica insurrección contra la genuina tradición nacional francesa, representada por el orden monárquico, el catolicismo y el clasicismo; y sus consecuencias sociales, políticas, económicas e ideológicas se encontraban en la base de la decadencia nacional que padecía Francia durante la mayor parte del siglo xIX y que se concretaba en la derrota ante Prusia, en la "Comuna", en el desastre de Fachoda y en el "affaire" Dreyfus, que había estado a punto de provocar una guerra civil. La Tercera República era la catalizadora, a través de sus instituciones, de aquellas ideas nefastas y destructivas; había consagrado la hegemonía de los enemigos internos de la Francia "real»: era el instrumento político de los "cuatro estados confederados», es decir, los protestantes, judíos, masones y «metecos» -0 sea, los desarraigados de la tradición nacional-, principales responsables de la decadencia de Francia. La República suponía, además, la democracia, el régimen electivo $y$, en consecuencia, la desorganización de la sociedad y el debilitamiento de la nación. Dada su naturaleza desintegradora, la democracia republicana suponía, asimismo, la división nacional y la subordinación del sagrado interés nacional a los intereses de los partidos políticos. Y su laicismo, propugnado por los dirigentes republicanos en contra de la Iglesia católica, repercutía negativamente en las costumbres y hábitos de la población francesa. A diferencia del protestantismo, el catolicismo encarnaba para Maurras - que no era creyente- los valores del orden y la jerarquía, y que se identificaba con la tradición nacional ${ }^{7}$.

La República llevaba, en fin, en virtud de sus principios electivos e igualitarios, a la centralización administrativa, ya que, al emanar su poder de la elección, el elegido, pretendiendo mantenerse en el poder, necesitaba tener sujeto al elector, para lo cual le era preciso a su vez el funcionario, y a éste extender la consiguiente red burocrática. En definitiva, la República era incapaz, en virtud de su propia estructura política, de descentralizar ${ }^{8}$.

6 Maurras, Charles, Romantisme et Revolution. París, Nouvelle Librairie Nationale. 1922, pág. 11.

7 MaurRas, Charles, "Trois idées politiques", en Romantisme et Revolution. París, Nouvelle Librairie Nationale, 1922, págs. 274 y ss.

${ }^{8}$ Maurras, Charles, Encuesta sobre la Monarquía. Madrid, 1935, págs. 705-706. 
La República, sin embargo, no sólo era incapaz de mantener un orden social estable de acuerdo con las leyes que regían la naturaleza social, sino que, de la misma forma y por las mismas razones, carecía de los medios necesarios para garantizar una política exterior independiente; suponía el reino de la irresponsabilidad y de la discontinuidad en la ejecución de las funciones políticas frente a las potencias -Alemania y Gran Bretaña, sobre todo- tradicionalmente enemigas de Francia ${ }^{9}$.

De este encuesta histórica, basada en los presupuestos ideológicos del «empirismo organizador», se desprendía la doctrina del «nacionalismo integral», que conducía necesariamente a la Monarquía. La defensa de la comunidad tradicional, orgánica, jerárquica y descentralizada, así como del interés nacional, tal y como se desprendía de la doctrina maurrasiana, exigía la restauración de la Monarquía tradicional y de los valores característicos del catolicismo y del clasismo estético. Todas las reformas necesarias en este sentido confluían en la transformación del régimen político. De ahí el típico lema maurrasiano «politique d'abord». Sólo la Monarquía disponía, a su juicio, de un poder lo sufientemente vivo, lo bastante regular y lo necesariamente duradero como para poder garantizar la continuidad de Francia como nación. Su principal argumento en favor del régimen monárquico era su esencial incompatibilidad con la democracia; la Monarquía tenía su propia "legitimidad", nacida de la herencia y, por lo tanto, era independiente del voto de las muchedumbres y se encontraba por encima de las discordias civiles y de los intereses sociales y económicos, constituyendo un poder autónomo, un poder en sí. Maurras insistía, asimismo, en su eficacia, al garantizar, mediante la herencia del oficio de gobernante, una mayor experiencia políticia. $Y$ que, en virtud de su propia posición social, podía promover el interés nacional por encima de cualquier otra instancia. En la Monarquía, el interés personal del gobernante, traducción del incoercible egoísmo propio de la naturaleza humana, y el interés público, lejos de oponerse, coincidian necesariamente. La herencia del poder político hace su fuerza, su continuidad paralelas a la fuerza, la continuidad, a la duración de la nación, al contrario que en la democracia, que implicaba necesariamente desorganización, división y discontinuidad ${ }^{10}$.

Naturalmente, el interés nacional y social exigían la supresión del parlamentarismo y de los partidos políticos, lo mismo que del sufragio universal, principal instrumento de desorganización y anarquía. En con-

\footnotetext{
- Maurras, Op. cit, pág. 22.

10 Maurras, Op. cit, págs. 96-97.
} 
secuencia, la Monarquía sería tradicional, reuniendo el monarca en su persona todos los poderes. El «pueblo» tendría representación en Cortes de carácter corporativo. Al mismo tiempo, libre de presión parlamentaria y electiva, el Estado recuperaría sus funciones naturales —orden público, finanzas y política internacional-, dejando todo lo demás a la iniciativa de los particulares. La Monarquía no sólo garantizaría una descentralización territorial, reconstituyendo las regiones y garantizando su autonomía, sino igualmente profesional, moral y religiosa. Se restaurarían los gremios, que garantizarían la armonía social entre los distintos estamentos y clases, así como la influencia de la Iglesia católica -bastión del ordenen el ámbito de la «sociedad civil». Y se reconstituiría la nobleza hereditaria, bajo la égida del monarca, lo cual garantizaría la continuidad social de la clase dirigente que necesitaba la nación. En este sentido, la política monárquica iría encaminada a una renovación de los restos de la vieja aristocracia mediante la fusión del impulso capitalista y urbano con los restos del orden jerárquico de la sociedad rural ${ }^{11}$.

Las ideas de Maurras tendrían su órgano de difusión en el diario L'Action Francaise y en una serie de entidades y organizaciones paraleleas ligadas a éste, y que lograrían una amplia influencia en la sociedad francesa. La negativa experiencia del affaire Dreyfus, que supuso la derrota de los sectores nacionalistas y clericales de la sociedad francesa frente a la izquierda y los liberales, persuadiría a Maurras de la necesidad de articular un contrapoder ideológico, que contrarrestara la influencia de las ideas domocráticas. No sería demasiado difícil, pues, interpretar el surgimiento de L'Action Française en términos gramscianos. La reforma intelectual y moral era, en la concepción maurrasiana, la condición esencial para la conquista del poder político. El sentimiento nacional por principio, el orden intelectual por base, la acción política como fin, tal fue, en esencia, el sistema a través del cual Maurras concibió en todo momento las relaciones entre las ideas y la acción. De esta forma, L'Action Française nació para ganar la guerra cultural: en una de sus obras más resonantes, L'Avenir de L'Inteligence, Maurras hacía un dramático llamamiento a una alianza entre los intelectuales y la aristocracia tradicional, con el fin de contrarrestar la influencia y el poder del "Dinero", encarnado en las instituciones republicanas ${ }^{12}$.

11 Maurras, Op. cit, pág. 307.

12 MauraAs, Charles, "L'Avenir de L'Intelligence», en Romantisme et Revolution. París, Nouvelle Librairie Nationale, 1922, págs. $85-86$. 
Las reflexiones de Maurras y la misma aparición de L'Action Française coincidian, de hecho, con un proceso de tranformación estructural de la sociedad gala. Una sociedad que se industrializa y que, en consecuencia, se urbaniza, y que, por ello, sufre un fuerte proceso de secularización. En el fondo, las ideas maurrasianas tienden a confundirse con la evocación nostálgica de una comunidad tradicional en vías de extinción. Ello podía percibirse claramente al estudiar sus bases sociales de sustentación. El movimiento organizado en torno a L'Action Française estaba compuesto por aquellos grupos sociales tradicionales que se sentían amenazados por el proceso de «modernización» capitalista: aristocracia, clases medias de provincias, clero católico - hasta, al menos, 1926-, militares y profesiones liberales. No obstante, en los años que median entre 1908 y el período de entreguerras, Maurras y su grupo disfrutarian de una amplia influencia ideológica en la sociedad francesa, que iría diluyéndose paulatinamente, hasta entrar en una profunda decadencia, a partir sobre todo de la condena de L'Action Française y de algunas de las obras de su máximo dirigente por parte del Vaticano, que, tras haberle apoyado en un principio, terminaría acusándole de instrumentalizar la religión para fines de carácter político, así como de paganismo, ateísmo y anticristianismo. Condena que tendrá una amplia repercusión en las sociedades europeas.

\section{RECEPCIÓN DEL PENSAMIENTO MAURRASIANO EN ESPAÑA (1914- 1930)}

La difusión del neotradicionalismo francés en algunos países de Europa oriental y mediterránea sería, en buena medida, la expresión ideológica de las necesidades que experimentan algunos estratos de las clases dominantes tradicionales, que, vinculadas orgánicamente a una estructura social preindustrial, se opondrían a los procesos de «modernización» de sus respectivos países. De esta forma, L'Action Française se convertiría en un modelo a seguir por parte de los intelectuales ligados a esas clases sociales de aquellos países en que el proceso de desarrollo capitalista se encontraba atrasado y donde, por consiguiente, los grandes latifundistas y las formas de explotación agrarias tenían todavía un importante peso social y económico. Estos grupos encontrarían en las obras maurrasianas un acervo de pautas ideológicas y de estrategias políticas que racionalizaran los intereses y las espectativas de aquellas fracciones de clase que se sentían amenazadas por los cambios sociales y políticos. Para ellos, el empirismo organizador tenía, además, el atractivo psicoló- 
gico de ser un desafío consciente a las corrientes democráticas y liberales, elaborado desde una perspectiva pretendidamente racionalista, naturalista, determinista, con pretensiones científicas y enormemente seguro de sí mismo. Daba así un aspecto aceptable e incluso de necesidad inmanente a determinadas actitudes escandalosas e intolerables por razones morales y sociales.

¿Qué difusión tuvieron en España —país que se caracterizaba por la preponderancia de las estructuras agrarias y el escaso desarrollo industrial- las ideas de Charles Maurras? Es significativo, en primer lugar, que ninguna de sus obras fueran traducidas al castellano hasta 1935, año en que se publica en España su obra más importante, Encuesta sobre la Monarquía. No obstante, esta ausencia de traducciones en modo alguno sería obstáculo para su recepción y críticas en algunos sectores de la intelectualidad española, que conocia ampliamente el idioma francés y que siempre se había sentido influida por la literatura y el pensamiento político galo. La recepción del pensamiento maurrasiano va a comenzar a hacerse notar, aunque de forma muy limitada, a partir del estallido de la Gran Guerra. Ya en aquel momento era evidente, al menos para las mentalidades conservadoras más conscientes, la crisis del sistema político de la Restauración, basado en los presupuestos ideológicos del liberalismo doctrinario, y la necesidad de nuevos planteamientos políticos e ideológicos. La práctica política de las clases conservadoras adolecía, en su opinión, de un pragmatismo y de una inmediatez muy próxima al suicidio. La conciencia de este hecho les empujaría a un interito de dotar al conservadurismo español de una cierta renovación ideológica al socaire de las corrientes foráneas nacidas en Europa, y particularmente en Francia. Comenzaría, entonces, a tomar cuerpo un proceso, que sólo cristalizaria de forma definitiva tras la caída de la Monarquía de Sagunto, de importación de las pautas contrarrevolucionarias europeas.

El historiador Eugen Weber, en su conocida obra sobre L'Action Française, reduce -erróneamente, a nuestro entender- la influencia maurrasiana en nuestro país, anterior a 1931, a la producción ideológica de José Martínez Ruiz, «Azorín» ${ }^{13}$. Efectivamente, sería "Azorín» el primero, aunque no el único, en exportar y, al mismo tiempo, exponer, de forma más o menos sistemática y selectiva, algunas de las ideas de Maurras. Hombre por entonces de Juan de la Cierva y miembro del Partido Conservador, «Azorín» juzgaba necesaria una política autoritaria y

${ }^{13}$ WEBER, Eugen, «L'Action Française». París, Fayard, 1985, pág. 419. 
«regeneracionista» para la cual era imprescindible una ideología. El conservadurismo español, sin embargo, desde la muerte de Cánovas, se había hundido, a su juicio, en un pragmatismo sin horizontes, ajeno a los temas ideológicos y culturales. Muy compenetrado con la cultura francesa de su tiempo, "Azorín" estimaba que la derecha española, so pena de suicidarse, debía seguir el ejemplo del conservadurismo francés, que, con Maurras, había logrado un claro predominio intelectual en su país. Siguiendo el modelo maurrasiano, la derecha española debería dar respuesta a la problemática política, social y estética, basando su teoría de la sociedad en Augusto Comte, defendiendo el clasicismo en el arte, viendo en las estructuras agrarias la «base de la continuidad» nacional y desdeñando de su perspectiva política el parlamentarismo y el sufragio universal, focos de anarquía, incoherencia y discontinuidad ${ }^{14}$. Al estallar la Gran Guerra, "Azorín» viaja como corresponsal a París y visita los locales de L'Action Française, en la que veía al grupo político-cultural "más coherente, compacto y lógico" de la derecha francesa ${ }^{15}$. E incluso se entrevistaría con el propio Maurras, con el fin de lograr su colaboración para el diario monárquico $A B C$, que no pudo lograrse, al desautorizarlo el gobierno francés. Poco después, sin embargo, L'Action Française ofrecería al escritor alicantino un banquete en homenaje a su labor proselitista y de apoyo a la causa francesa en la guerra.

Otro escritor influido por Maurras fue José María Salaverría. Con motivo de la vista, en mayo de 1938, del ideólogo galo a la España de Franco, Salaverría confesaría que gran parte de su producción ideológica estuvo, por lo menos desde 1914, en permanente diálogo con Maurras, el «luchador pertinaz» ${ }^{16}$. Desde una perspectiva igual a la defendida por "Azorín", Salaverría, que nunca militaría en ningún partido político, se sentía preocupado por el porvenir de la derecha española, que carecía del apoyo de los intelectuales; lo cual contrastaba ampliamente con el discurso "fino, universitario y fogoso" que el conservadurismo francés había logrado articular con Maurras y otros ideólogos, como Peguy y Barrès ${ }^{17}$. De hecho, la influencia maurrasiana es patente en una de sus obras más famosas, La afirmación española, en la que Salaverría defiende un nacionalismo tradicionalista y antieuropeísta, y en la que, muy en concordancia con Maurras, veía en la actitud «romántica», represen-

${ }^{14}$ «Azorín», Un discurso de la Cierva, Madrid, Renacimiento, 1914, págs. 87-88, 148$149,163-165$ y ss.

15 "Azorín", Con bandera de Francia, Madrid, Biblioteca Nueva, 1950, pág. 85.

16 «El luchador pertinaz», en $A B C$, Sevilla, 18-V-1938.

17 "Doctrina conservadora", en $A B C, 9-\mathrm{XII-1916.}$ 
tada por la «generación» del 98, un peligroso germen de individualismo crítico, propagador de posturas antipatrióticas, antimilitaristas y derrotistas, culpables de la "decesdencia» nacional. "Tenían el vicio de la revolución -diría Salaverría, refiriéndose a los «noventayochistas»-como buenos románticos que eran» ${ }^{18}$.

De la misma forma, encontramos en el escritor vasco la pretensión de erradicar cualquier perspectiva de cambio social cualitativo, recurriendo, como lo hacía el "empirismo organizador", a la asimilación epistemológica entre "naturaleza» y «sociedad». «Acostumbrados al uso de la rebeldía y del sufragio en masa, el obrerismo no sólo se alza contra los gobiernos burgueses; en realidad, están haciendo oposición a la $\mathrm{Na}$ turaleza, conspiran contra la Naturaleza» ${ }^{19}$.

Tampoco fue inmune a la influencia de Maurras el filósofo catalán Eugenio D'Ors, quien, en sus continuos viajes a París, conoció y entabló amistad con Maurras con el líder intelectual de L'Action Française. La doctrina maurrasiana era para D'Ors la manifestación más coherente y lógica de una nueva sensibilidad ideológica, política y estética, radicalmente contraria a los principios liberales de la Revolución francesa. Muchos de los presupuestos ideológicos de la Política de Misión d'orsiana tienen una indudable impronta maurrasiana,en particular la insistencia en la jerarquía, el corporativismo gremialista y la Monarquía. De la misma forma, D'Ors, como crítico de arte, desdeñaba el «romanticismo» en la estética, identificándolo con la hipertrofia del "yo", con la rebeldía individual frente a las "leyes" objetivas que rigen la vida de las socieda$\operatorname{des}^{20}$.

Ahora bien, D'Ors distaba mucho de ser un maurrasiano dogmático; y su aprobación de aquellos principios ideológicos y políticos fue tan sólo parcial. De un lado, el filosofo catalán se mostraba partidario de un extraño cosmopolitismo y, por lo tanto, adversario del principio de las nacionalidades, reprochando a Maurras la asociación del nacionalismo con la Monarquía, que era, a su juicio, la institución política ecuménica por excelencia; $y$, de otro, desdeñaba el positivismo comteano que servía de base a las doctrinas del ideólogo galo ${ }^{21}$.

18 Salaverría, José María, La afirmación española. Estudios sobre el pesimismo español y los nuevos tiempos. Barcelona, Gustavo Gili, 1917, pág. 55.

${ }_{19}$ Salaveraía, José María, En la vorágine. El fervor multitudinario. Conjeturas. Madrid, Caro Raggio, 1919, pág. 77.

${ }_{20}$ D'ORS, Eugenio, Nuevo Glosario. Tomo II. Madrid, Aguilar, 1947; pág. 574.

${ }^{21}$ D'Ors, Op. cit., págs. 349-350. 
El carlismo no permaneció ausente de la influencia maurrasiana, al menos en sus ideólogos más conscientes y abiertos a las novedades doctrinales venidas del exterior. Así, Víctor Pradera, el discipulo por excelencia de Juan Vázquez de Mella, estaba suscrito a L'Action Française y consideraba a Maurras, cuyas ideas sobre la Monarquía y la descentralización regional recogía en sus discursos y libros de carácter doctrinal, como «uno de los grandes cerebros del mundo» ${ }^{22}$. De la misma forma, Salvador Minguijón era un buen conocedor de la ideología del nacionalismo integral y veía en L'Action Française un modelo a imitar en España, para el logro de la necesaria acción proselitista entre los intelectuales españoles, así como la renovación ideológica del carlismo como movimiento político ${ }^{23}$.

Otro de los grupos del conservadurismo español que se vio influido por L'Action Française fue el maurismo. De hecho, el propio Maura - que nunca abdicaría de sus ideas liberales- conocía las ideas de L'Action Française y mantendrá correspondencia con Maurras. En 1909, Maura recibiría la visita de uno de los redactores del diario maurrasiano, Pierre Gilbert, que venía a España en viaje de estudios, y que entregaría al político mallorquín, entre otras obras, la Encuesta sobre la Monarquía y El romanticismo francés de Pierre Lasserre. El mismo Maurras, por otra parte, tenía un buen concepto de Maura como político, considerándole como el «más eminente defensor del orden europeo» y como «el ilustre defensor del regionalisino y del autoritarismo español» ${ }^{24}$. En agradecimiento al reiterado apoyo que Maurras y su grupo dieron a su política en la opinión francesa, Maura solidarizaría, en una amistosa carta inmediatamente publicada en L'Action Française, con la suerte de Maurras, al ser éste procesado a causa de sus campañas en contra de la III República; lo cual merecería un amistoso intercambio epistolar entre ambos ${ }^{25}$.

El maurista más compenetrado con los principios del «empirismo organizador» y el «nacionalismo integral» fue Antonio Goicoechea, jefe de las Juventudes Mauristas, para quien L'Action Française era un grupo político-intelectual «digno de toda admiración por su decisión patriótica,

${ }^{22}$ Pradera Victor, Obra Completa. Tomo I. Madrid, Instituto de Estudios Políticos. 1945; pág. 324.

${ }^{23}$ MinguiJon, Salvador, La crisis del tradicionalismo en España. Zaragoza, Biblioteca de Tradición y Progreso, 1914; pág. 22. Minguluón, Salvador, Al servicio de la Tradición. Ensayo histórico-doctrinal de la concepción tradicionalista según los maestros de la contrarrevolución. Madrid, 1930, págs. 193-194, 234 y ss.

${ }^{24}$ Archivo Antonio Maura. Legajo 378, “La letre de Monsieur Maura», en L'Action Française, 8-11-1913.

${ }^{25}$ Archivo Antonio Maura. Legajo 378, cartas 23-II-1913 y otra sin fecha. 
por su valer colectivo y personal, por su selecto y fino espíritu literario" ${ }^{26}$. Goicoechea utilizaba el «empirismo organizador» para refutar los principios ideológicos del orden demoliberal; a su entender, el positivismo, tal y como Maurras lo interpretaba, había demostrado, mediante la asimilación epistemológica de la sociedad a la "naturaleza", la imposibilidad de un orden social igualitario. Tras la aportación del Maurras, el ambiente intelectual se encontraba marcado por la animadversión a los «falsos dogmas" de la Revolución francesa ${ }^{27}$. El político maurista se hacía eco, asimismo, de las formulaciones maurrasianas relacionadas con el regionalismo y la descentralización. El proceso descentralizador que España precisaba exigía la institución monárquica como necesario complemento, que impidiera la disgregación nacional y que, al mismo tiempo, fuese el más serio y firme soporte del regionalismo. «No olvidéis - señalabaque toda obra de regionalización exige un robustecimiento inflexible, vigoroso del Poder supremo (...) la Monarquía es en España una fuerza viva, la representación irreemplazable de la tradición nacional y del principio de unidad frente al fraccionamiento de un territorio que la Naturaleza ha dividido en pedazos" ${ }^{28}$.

No faltaban, sin embargo, detractores a Maurras en España. José Ortega y Gasset no dedicaria, por su parte, excesiva atención, a pesar de su admiración por la literatura francesa, a Maurras y su grupo, que tan sólo merecería una casi accidental y recoleta página en sus obras completas, donde se señalaba la artificiosidad y el escaso porvenir político de las construcciones ideológicas del padre del nacionalismo integral. Para Ortega, los razonamientos de Maurras eran tan sólo "tópicos ornamentales, críticas caprichosas y vagos proyectos" ${ }^{29}$.

Mayor atención merecería Maurras a Manuel Azaña, quien dedicaría un capitulo de su obra Estudios sobre política francesa contemporánea a L'Action Française. En un principio, Azaña reconocía talento literario y originalidad doctrinal a Maurras, a quien calificaba de «polemista vigoroso». Su nacionalismo integral le parecía, sin embargo, insoportable y no era más que una muestra del odio que inspiraban a Maurras la demás

${ }^{26}$ GolcoeCHEA, Antonio, El problema de las limitaciones de la soberanía en el derecho público contemporáneo. Madrid, Real Academia de Ciencias Morales y Políticas, 1923, pág. 218.

${ }^{27}$ GolcoeCHEA, Antonio, La crisis del constitucionalismo moderno. Madrid, Voluntad, 1925; pág. 36.

${ }_{28}$ GolcoeCHEA, Antonio, El proyecto de Estatuto Regional y las aspiraciones autonomistas. Madrid, Real Academia de Jurisprudencia y Legislación, 1919; pág. 49.

${ }^{29}$ OrTEga y Gasset José, Obras Completas. Tomo X. Escritos políticos. I (1908-1921). Madrid, Revista de Occidente, 1969, pág. 210-211. 
naciones. "Maurras, que establece como norma suprema el interés nacional, se enfurece con los ingleses cuando ofrecen a Francia su amistad porque les conviene. Maurras querría tal vez que su pais hiciese mangas y capirotes del mundo, atento solo a la razón francesa, y que los demás pueblos anduviesen, sin consultar el interés propio, pendientes de los deseos y de los caprichos y del humor de la nación francesa. La actitud es insoportable. Todo en ella respira odio, descontento y ambición. Es demasiado. Si Maurras tuviera razón o, sin tenerla, triunfase, habría que transplantar Francia a Sirio, o el mundo haría con ella lo que ha hecho con la Alemania imperial. Mejor que con ese maquiavelismo sirvieron el interés nacional los que en un momento dado pusieron de parte de Francia el derecho y la razón universales» ${ }^{30}$. Sería, sin embargo, Miguel de Unamuno quien de forma más sañuda y radical se enfrente con los postulados del neotradicionalismo francés y, en particular, con su instrumentalización del catolicismo para fines políticos. En temprana fecha, Unamuno se hizo eco de las polémicas desarrolladas en Francia en torno al carácter político del "romanticismo", rechazando las interpretaciones clasicistas de Maurras y sus acólitos, en las que veía tan sólo la «pedantería racionalista y clasicista" del nacionalismo galo ${ }^{31}$. No pasó tampoco inadvertida a Unamuno la campaña maurrasiana de "Azorín», cuya defensa del positivismo conteano le parecía una concesión al materialismo; así como su aceptación del clasicismo lo era a la barbarie nacionalista, que ninguna mentalidad liberal podía aceptar ${ }^{32}$. Exiliado en París durante la Dictadura primorrevirista, Unamuno - que recibiría ataques de L'Action Francaise durante su estancia en la capital gala - tendría oportunidad de leer, por vez primera, la Encuesta sobre la Monarquía, obra que le producirá una penosa impresión. Y no dudará en decir que Maurras ofrecía, en aquella obra, "carne ya podrida, procedente del matadero del difunto conde José de Maistre». Ante todo, lo que escandaliza al escritor vasco es el nacionalismo estrecho, agresivo y omnicomprensivo de Maurras, lo mismo que su instrumentalización de hecho religioso para fines políticos. «La patria del cristiano - dirá - no es de este mundo. Un cristiano debe de sacrificar la patria a la verdad» ${ }^{33}$.

La condena de L'Action Française y de algunas de las obras de Maurras por parte de la Santa Sede provocaría en España alguna que

\footnotetext{
30 Azaña, Manuel, Obras Completas. Tomo I. México, Oasis. 1968, pág. 374.

${ }^{31}$ DE Unamuno, Miguel, Ensayos. Tomo II. Madrid, Aguilar. 1964, pág. 1120.

32 De Unamuno, Miguel, Pensamiento político. Madrid, Tecnos, 1965, pág. 473.

${ }^{33}$ DE Unamuno, Miguel, La agonía de cristianismo. Madrid, Espasa-Calpe. 1975, págs.
} 16-17. 
otra controversia y comentarios respecto a la significación ideológica del nacionalismo integral. Los diversos sectores del catolicismo español se vieron obligados a dar su opinión ante un tema de indudable transcendencia ideológica y política. Aunque de manera excepcional, no faltará algún admirador de Maurras que, como Álvaro Alcalá Galiano, marqués de Castel-Bravo y Grande de España, acuse al Vaticano de traicionar a uno de sus grandes defensores ${ }^{34}$. Pero aquel exabrupto fue incidental; $y$ la actitud dominante sería precisamente la contraria. En este sentido, es preciso destacar la intervención del democristianc catalán Carles Cardó, quien, con motivo de la condena, analizaría de forma muy sistemática la ideología maurrasiana, con la que, visto su alto nivel erudito, parecía estar muy familiarizado. En opinión de Cardó, Maurras era el «Rousseau de la derecha», un pagano que profesaba doctrinas abiertamente inmovilistas de contenido profundamente anticristiano. «Para él, el mundo humano está fatalmente gobernado por las leyes mecánicas, físicas, biológicas. Las sociedades humanas tienen la fijeza de los sistemas siderales" ${ }^{35}$.

De hecho, la condena del Vaticano supondría un serio handicap para la difusión del pensamiento maurrasiano en España. Por otra parte, era evidente que las clases dominantes tradicionales continuaban sin ser conscientes de la necesidad de una cierta actividad intelectual y doctrinal contrarrevolucionaria que diera legitimidad a su posición social. Y permanecerán hasta el advenimiento de la Segunda República en esa apatía situacional que tanto alarmaba a los intelectuales de la derecha y que tan sólo el contraataque de las clases subordinadas y su tendencia, cada vez más patente y explicita, de derribar el sistema socioeconómico vigente y sus relaciones de producción les obligaría a abandonar. Será entonces cuando, mediante la fundación de "Accion Española» en diciembre de 1931, los planteamientos ideológicos de la escuela maurrasiana ejercerían una mayor influencia en la sociedad española.

${ }^{34}$ "Acción Francesa y el Vaticano", en $A B C, 20-1-1927$.

35 "L'Esglesia i L'Action Francaise», en Paraula Cristaiana, n. ${ }^{\circ} 24$, decembre de 1926. Inserto en CARDó, Carles, La moral de la derrota i altres assais. Barcelona, Ariel, 1959, págs. 197 y ss. 